\title{
Entrar en la danza o desaparecer de la escena. Las religiones ante los cambios de paradigma
}

\author{
Enter into the dance or disappear. \\ Religions before paradigm shifts
}

\author{
Geraldina Céspedes*
}

\begin{abstract}
Resumen
Estamos en una época de cambios cruciales en la que se están dando verdaderas mutaciones en la vida de las personas y de las sociedades. Las religiones, que muchas veces muestran resistencia al cambio y miedo a lo nuevo, se ven sacudidas en sus mismos cimientos por todos los movimientos ligados al cambio de época y al cambio de paradigma. El artículo plantea cómo las distintas religiones hoy están en una encrucijada en la que tienen que tomar una decisión: o entrar en la danza de la vida y de la historia, practicando los movimientos y aprendiendo nuevos pasos, o simplemente ellas desaparecerán de la escena como instancias significativas e inspiradoras para personas adultas que saben distinguir entre la copa y el vino. Si las religiones quieren seguir ofreciendo un horizonte de sentido para la humanidad, aportando sus energías y su fuerza transformadora para rehacer nuestro mundo, tienen que resituarse y reconfigurarse, repensando y recreando sus prácticas, sus interpretaciones y sus lenguajes.
\end{abstract}

Palabras-clave: religiones; posreligional; espiritualidad; cambio de paradigma; sagrado.

\begin{abstract}
In current times we have noticed crucial changes with real mutations in the lives of individuals and societies. Religions, which often show resistance to change and fear the new, are shaking in its foundations by movements linked to changing times and changing paradigm. This article discusses how the different religions are now at a crossroads where you have to make a choice: acquire new ways and steps, or simply disappear as significant and inspiring instances for adults. If religions want to keep offering such a horizon of meaning for humanity, bringing their energy and transforming power to remake our world, they have to be placed differently and reconfigured, as well as to rethink and recreate their practices, interpretations and languages.
\end{abstract}

Keywords: Religion; Post-religional; Spirituality; Paradigma shift; Sacred

Artículo recibido el 17 de octubre de 2014 y aprobado el 03 de marzo de 2015.

* Doctora en Teología y Cristología (Universidad Pontificia Comillas) y Profesora de Teología y Cristología Feminista de la Escuela Feminista de Teología de Andalucía. País de origen: República Dominicana. E-mail: dissgeral@hotmail.com. 


\section{Introducción}

Nunca antes en la historia de la humanidad nos habíamos enfrentado a tantos cambios y a tantas sacudidas en los distintos aspectos de nuestra vida y de la vida del mundo. Se puede decir que el piso sobre el que estábamos cimentados se está moviendo y lo que está asentado sobre ello se tambalea o empieza a derrumbarse.

Estamos en un cambio de época en el que se están dando mutaciones tan sustanciales y radicales que si no cambiamos desde lo profundo y entramos en la dinámica de esta mudanza, el edificio de nuestras creencias podría derrumbarse. Muchas personas estamos percibiendo que en nuestros sistemas de creencias y en nuestras estructuras de pensamiento religioso hay cosas que sencillamente ya no se sostienen o se han vuelto incomprensibles y extrañas para el ser humano de estos tiempos modernos.

Los seres humanos de hoy, en general, tenemos una nueva conciencia y una nueva visión e interpretación del funcionamiento de las cosas, de la evolución de la vida, del desarrollo de la ciencia. Esa nueva visión no siempre ha sido bien acogida en el ámbito religioso. Aceptamos que todo lo demás pueda cambiar y pueda ser sacudido, pero hay una tendencia a mantener inamovible el edificio del mundo de nuestras creencias y de nuestras teologías. Es por ello que podemos afirmar que dentro de todos los cambios que se están dando en el mundo, el ámbito de las religiones y de los sistemas de creencias son los que, por lo general, tienen más resistencia al cambio y un mayor miedo a lo nuevo.

Sin embargo, el cambio toca a la puerta y de algún modo hay que responder. ¿Le abriremos o reforzaremos las cerraduras? Alguna respuesta tendrá que darse, de parte de las religiones, ante las nuevas situaciones y el nuevo clima en el que está viviendo hoy día gran parte de la humanidad. No se puede seguir con esquemas y formas caducas de vivir la fe y de explicar las cosas. El cambio de paradigma tiene que darse porque hay cuestiones que son insostenibles para un 
creyente adulto y para un mundo que ha evolucionado. En el ámbito religioso, o nos abrimos a los grandes cambios de paradigmas que se están dando hoy en nuestro mundo, o simplemente las religiones quedarán como piezas de museo o como los objetos obsoletos que guardamos en nuestras casas que nos evocan recuerdos de tiempos pasados, pero que ya tienen muy poca utilidad.

El propósito de este artículo es plantear cómo los grandes cambios que están sacudiendo nuestro mundo también sacuden a las religiones, por más que ellas muchas veces se resistan a entrar en esta nueva danza que tiene un nuevo ritmo y un nuevo escenario. Ante la nueva visión que nos va llegando en esta nueva era de la sociedad del conocimiento y la innovación, las religiones, si quieren seguir ofreciendo un horizonte de sentido para la humanidad, tienen que resituarse y reconfigurarse, repensando y recreando sus prácticas, sus interpretaciones y sus lenguajes.

\section{Ante la emergencia de un nuevo paradigma}

A lo largo de la historia, las religiones se han visto en situaciones en las que un cambio de paradigma ha puesto en cuestión sus mismos cimientos. Sin embargo, no siempre ellas se han dejado afectar e impactar por los nuevos vientos que han soplado en determinadas épocas históricas. Si echamos una mirada a la historia, encontramos circunstancias diversas en que las religiones y movimientos religiosos ante lo nuevo han huido (fuga mundi) o han reforzado sus cerrojos, encerrándose en sí mismas sin apenas diálogo con el mundo y con los clamores de su tiempo. Hay también casos en los que, sin ningún afán de contemporizar, ha habido intentos de salir al encuentro de lo que sucedía en el mundo y esfuerzos por entablar un diálogo.

Asistimos hoy a una situación de crisis plurales y de cambios acelerados que no son superficiales y pasajeros, sino profundos y sustanciales. Por eso se habla de cambio de época y de cambio de paradigmas. Este cambio epocal y de paradigmas 
está afectando seriamente a las religiones, aunque muchas personas no son conscientes de ello o quizá les dé vértigo sólo pensar en el maremoto que se avecina para las religiones que han funcionado como estructuras fijas e inamovibles. Hay quienes ya se han situado a la defensiva, cerrándose a la evidencia y a lo que podemos constatar día a día en personas y grupos concretos para quienes las religiones organizadas están dejando de ser instancias significativas y configuradoras de sus vidas.

Está emergiendo con fuerza un nuevo paradigma religioso que estamos llamando posreligional (también podría ser denominado transreligional). Necesitamos analizar este nuevo fenómeno religioso que va tomando auge en distintos lugares del mundo y que se vislumbra será el modelo predominante y con más tendencia al crecimiento. Las religiones que quieran renovarse y ubicarse en este cambio de época tendrán que abrirse y acoger las riquezas y posibilidades que trae este nuevo paradigma posreligional, asumiendo las implicaciones que se derivan del mismo. Ubicarse en un nuevo paradigma es un riesgo en el que habrá pérdidas y ganancias para las religiones. Es sin duda un atrevimiento que supone entrar en un terreno inseguro y movedizo que puede dar miedo y desencadenar una crisis aún más profunda. Pero en ese suelo también puede brotar lo nuevo y ahí podemos levantar un edificio religioso mucho más sencillo y abierto, con unos cimientos nuevos que sean más profundos y, por lo tanto, más consistentes.

\section{Tiempos de poli-crisis, ¿tiempos de poli-oportunidad?}

La humanidad atraviesa por una de las crisis más profundas y complejas. Son crisis plurales e interconectadas que en el marco del fenómeno de la globalización se extienden a lo ancho y a lo largo de la geografía, de modo que no es asunto de unas sociedades específicas, sino de la sociedad en general. Retomando los planteamientos de Edgar Morin que ya en 1929 hablaba de que había varias crisis interconectadas. Esta poli-crisis lo que viene a revelar es que hay un problema de fondo, un problema serio de raíz: el sistema no sirve, el modelo con 
el que se ha funcionado ya está desgastado. Cuando en nuestra persona y en nuestras instituciones hay una poli-crisis, es hora de cambios radicales, no de pequeños arreglos o de poner remiendos al vestido. Si todo está colapsando, es que los fundamentos que se pusieron en otros tiempos ya no sirven para sostener el edificio. Entonces hay que tener el coraje de demoler y empezar de nuevo. Es tiempo de situarnos en otro marco de comprensión, es decir, en un nuevo paradigma. Cambiar de paradigma es cambiar la forma en que una determinada sociedad organiza e interpreta la realidad. La constatación de una situación de policrisis tendría que llevarnos a acoger los nuevos paradigmas que muchas veces emergen entre los mismos escombros del paradigma anterior; en otras ocasiones los paradigmas nuevos coexisten con los viejos. En el mundo de las religiones tenemos muchos ejemplos de esta situación.

Podríamos decir que estamos en tiempos de una poli-crisis en que todos los aspectos de la vida humana y de la vida en sociedad están implicados y están siendo zarandeados. Si analizamos seriamente los distintos aspectos de la vida de las personas nos damos cuenta que todos están en cuestionamiento, que hay un malestar (a veces manifiesto y otras veces latente), un sentimiento de que hay cosas que ya dieron de sí, que ya no puede ser así en estos tiempos modernos. La sensación es que hay cuestiones que ya se desgastaron, que ya dieron lo que tenían que dar y hoy necesitamos otras ideas, interpretaciones y estructuras nuevas en las que apoyarnos.

A veces la percepción de la poli-crisis es tal, que podemos experimentar la sensación de que todo se está desmoronando y estamos al borde de que colapsen las estructuras en las que nos habíamos apoyado como suelo firme y seguro. El cambio de paradigma al que nos está llamando la situación de poli-crisis viene dada por la misma ruptura que experimentamos entre el transcurrir de la vida y lo que proclaman las religiones. Vivimos un desfase, una distancia que muchas veces es abismal, entre la vida corriente, las preocupaciones cotidianas, los grandes cambios culturales y lo que predican las religiones. Algo no anda bien y no se puede 
seguir con esa esquizofrenia, pues es como vivir en una doble vida. La mayor parte del tiempo, la vida de las personas transcurre en la atmósfera del siglo XXI, de la era de la sociedad del conocimiento y la innovación. Pero muchas veces cuando participamos en los rituales de la religión, es como si retrocediéramos algunos siglos atrás.

Aunque las religiones tienen muchas veces la pretensión de la perennidad, de ser inamovibles y de bregar con verdades eternas, lo cierto es que ellas son afectadas por los cambios y son sacudidas profundamente por los grandes cambios que se van dando en el mundo. El mundo de las religiones no está vacunado contra todas estas crisis y transformaciones que se están dando en nuestro mundo. Por el simple hecho de existir en nuestro mundo y en cuanto fenómenos culturales, ellas son tocadas (y muchas veces trastocadas) por los grandes cambios que se van dando en nuestro mundo. Para comprender la crisis de las religiones y el clamor por lo nuevo que se esconde en cada crisis, hay que ubicarse en las grandes crisis y transformaciones que se están dando en nuestra cultura. Las crisis en las religiones no se pueden comprender si no es en el marco de las crisis culturales, pues las religiones se sitúan en el corazón de las culturas y las culturas de algún modo han emergido de una matriz religiosa. Dada esta imbricación entre religión y cultura, hay que plantear un marco de comprensión que abarque tanto a las religiones como a las culturas. Tanto la visión de Clifford Geertz como la de Paul Tillich iluminarían muy bien esta relación entre religión y cultura. Ambos consideran que religión y cultura son inseparables. Para Tillich la religión es la substancia de la cultura y la cultura es la expresión de la religión, y para Geertz las religiones son sistemas simbólicos muy relacionados con la cultura.

Si esto es así, las grandes transformaciones culturales y los cambios de paradigmas tendrían que afectar profundamente a las religiones. De hecho las religiones no quedan fuera de ese mar de cambios que se están dando en nuestro mundo. Lo que sucede es que muchas veces las instituciones religiosas son lentas para reaccionar y reacomodarse en una sociedad en estado de conmoción. Las instituciones religiosas están siendo sacudidas y cuestionadas desde los grandes 
cambios que se dan en nuestro tiempo. El piso de las instituciones religiosas también se está moviendo y está reclamando una nueva reconfiguración y actualización de sus estructuras y sus sistemas de creencias.

Si las religiones saben situarse en estos tiempos (integrando su capacidad adaptativa con su capacidad crítica), las poli-crisis de nuestro mundo pueden llegar a convertirse en su poli-oportunidad, inventando formas variadas y nuevas en las que recrear sus intuiciones más significativas y que aún serían un aporte válido para nuestro mundo. Para acceder a las múltiples oportunidades que pueden estar soterradas bajo los escombros de lo que se ha derrumbado, hay que estar dispuesto a entrar en la dinámica muerte-vida, pérdida-ganancia.

\section{Una imagen de Dios insostenible}

Al preguntarnos qué es hoy día lo insostenible desde el punto de vista religioso, una se encuentra con una serie de afirmaciones y prácticas que formarían una lista larga (sería interesante que las personas y las instituciones religiosas se autoanalizaran y se atrevieran a hacer su propia lista de aquellas creencias, posturas y prácticas que resultan chocante para la sensibilidad actual). Sin embargo, lo que considero crucial y decisivo es ir a la raíz de donde brotan esas afirmaciones y prácticas. Y considero que lo que está a la base es la imagen de Dios, pues nuestras imágenes de Dios tienen el poder de inspirar y desatar posturas y prácticas que pueden liberarnos u oprimirnos; que nos dejan petrificados al borde del camino o que nos ponen a caminar o incluso a abrir nuevos caminos; que nos aprisionan dentro de una jaula o que nos hacen volar, traspasar fronteras y conocer nuevos paisajes.

Cuando nos adentramos en la cuestión de las crisis en las religiones y sus formas obsoletas y/o extrañas de pensar y practicar lo religioso, constamos que el problema raíz tiene mucho que ver con la concepción de la divinidad desde la que funcionamos. Si no hay un cambio en la imagen de Dios, se hace difícil estrenar 
nuevas prácticas socio-religiosas y elaborar otras teologías que muestren que, como plantea Elizabeth Johnson, "hay modos de pensar sobre Dios que todavía desconocemos" (JOHNSON, 2002).

Entonces hay que cambiar de Dios para poder cambiar de vida, para poder cambiar este mundo, como afirma el obispo Pedro Casaldáliga (CASALDÁLIGA, 2011, p. 2), pues lo que sea ha hecho insostenible (en el sentido de que ya no se sostiene ni nos sostiene) fundamentalmente es apoyarse en una imagen de Dios y en unas formas de vivir lo religioso que corresponden a un estadio infantil o a épocas de la evolución de la humanidad que quedaron atrás. Necesitamos un Dios para hoy y para un creyente adulto y eso implica atrevernos a "matar nuestros dioses”, como plantea J. M. Mardones (MARDONES, 2006).

Las religiones tienen que plantease ir más allá de las religiones y atreverse a nacer de nuevo, es decir, salir de la carcasa o de la armadura de sus formas institucionales que atrapan o asfixian al mismo Dios y a las personas. Estas instituciones religiosas muchas veces funcionan fundamentadas en imágenes de Dios distorsionadas o alienantes.

Las imágenes distorsionadas de Dios son las que han distorsionado el mundo, las que han distorsionado la visión que tenemos sobre las distintas realidades humanas (como la visión de la sexualidad, la relación con la naturaleza, la concepción de la política, la relación entre hombres y mujeres, etc.). Es crucial cambiar o sanar las imágenes de Dios con las que nos manejamos.

En nuestro mundo hoy los cambios son mucho más rápidos, más perceptibles y con un mayor efecto de contagio. Pero en materia religiosa, a veces vamos a estilo tortuga, olvidando que el Espíritu va como una paloma, impulsándonos a volar, a la agilidad para movernos y seguir el ritmo de la historia. Se podría decir, en lenguaje de la tradición religiosa cristiana a la que pertenezco, que cuando estamos abiertas al Espíritu y le escuchamos marchamos al ritmo de los grandes cambios de nuestra historia. Pero cuando no le escuchamos perdemos el tren de la historia y nos quedamos desfasados, realizando prácticas religiosas con 
posturas, lenguajes, ropajes y estilos de organización y funcionamiento que nada tienen que ver con la sensibilidad actual. Esto lo percibió muy bien el cardenal Carlo María Martini cuando dijo: "La Iglesia se ha quedado atrás 200 años"1.

\section{La emergencia de lo religioso y la ruptura con las religiones}

Hay dos elementos que caracterizan la cuestión religiosa en este cambio de época. El primero es que estamos asistiendo a una época de gran efervescencia de la sensibilidad religiosa, hay un creciente interés por lo religioso o pseudoreligioso, tal como se puede apreciar en que hoy día son cada vez más los seres humanos que dedican algo de tiempo y de recursos para participar en algo que tenga que ver con lo religioso.

Hoy día es más evidente que nunca cómo el ser humano anda en una interesante búsqueda espiritual, que ve la necesidad de encontrar sentido y orientación a su vida, que da importancia a los valores emergentes. Contra todo pronóstico realizado en épocas anteriores y que vaticinaban un abandono de lo religioso, hoy día hay mucha demanda de lo religioso. Sea denominado como "rebelión espiritual” en palabras de J.L. Aranguren, o como "reencantamiento del mundo", "retorno a lo sagrado" o "vuelta de lo religioso", lo cierto es que se trata de un fenómeno constatable tanto en la vida cotidiana como a nivel personal y colectivo.

Estamos ante una situación nueva y característica de la modernidad en la que las personas no están pasando de largo ante la cuestión religiosa, sino que estamos en una era de la religión en expansión. Esta situación inesperada, en cuanto que se vaticinaba una ruptura entre modernidad y religión, ha llevado a que eruditos como por ejemplo, como el teólogo y sociólogo Peter Berger, una de las figuras destacadas en sociología de la religión, se replanteara la tesis sobre la secularización generalizada. Se pensaba que la entrada de la modernidad iba a

\footnotetext{
${ }^{1}$ Véase la última entrevista al Cardenal Martini, que ha quedado como su testamento espiritual (MARTINI, 2012).
} 
suponer una secularización de la sociedad, pero los datos de lo que está sucediendo en el mundo, con la ebullición religiosa que se manifiesta en una pluralidad de nuevas expresiones y nuevos movimientos, manifiestan que las religiones han vuelto para quedarse ${ }^{2}$.

Pero no se trata de una vuelta a las religiones en su configuración tradicional ni la religión sociológica. Más bien con ellas se da una ruptura y un distanciamiento, sobre todo con respecto a lo que en ella hay de estructura, de normas establecidas. Es como si los seres humanos se sintieran a gusto con el espíritu y las intuiciones más auténticas y profundas de las religiones, pero a disgusto con sus formas institucionalizadas. Va cobrando cada vez más fuerza la tendencia a vivir lo religioso de una forma libre y sin vínculos normativos con las instituciones religiosas. Es la desregularización de la religión, tal y como plantea A. Frigerio3.

Se podría decir que si el ser humano se está encantando o re-encantando con la espiritualidad, también se está desencantando cada vez más de las religiones en su forma más institucionalizada y estructurada. Por eso cada vez más y en mayor número las personas están haciendo sus búsquedas y sus experiencias espirituales al margen de las estructuras tradicionales de las religiones, que ofrecen ciertamente muchos y variados "productos religiosos" pero no los que ellos y ellas andan buscando. Es por eso que muchas personas están diseñando nuevas formas de vivir su dimensión religiosa. La gente está reinventando las religiones o diseñando, en muchos casos, su propia religión, pues desea formas más libres, frescas y espontáneas de vivir su espiritualidad. Sin entrar a hacer juicios ni análisis más profundos, lo que podemos afirmar es que esta búsqueda es parte de su condición de adulto, de su conciencia de autonomía y su condición de sujeto.

\footnotetext{
${ }^{2}$ Berger destaca cómo hay dos excepciones en la afirmación de que la modernidad no mató la religión: el caso de los países europeos y el de las clases intelectuales. Pero lo del secularismo no se convirtió en fenómeno mundial. Lo que sí sucedió fue que la gente recreó y reinventó nuevas formas de vivir la fe. Esto lo expresó muy claro Berger cuando en su conferencia sobre globalización y religión en el Pew Forum en diciembre de 2006 planteó que la religión ha evolucionado hacia el pluralismo y no hacia el secularismo (cfr. BERGER, 2006).

${ }^{3}$ Véase el estudio de FRIGERIO, 2000.
} 
Si las religiones no ofrecen respuesta a las preguntas más acuciantes de las personas más inquietas y críticas; si no ofrecen espacios saludables y liberadores donde las personas puedan recrear y expresar su dimensión de hondura; y si no acogen a las personas como seres humanos adultos, capaces de decidir sobre los distintos aspectos de sus vidas, entonces no será nada extraño que se dé un abandono cada vez y más creciente de las instituciones religiosas. En la medida en que las personas toman conciencia de la obsolescencia de los sistemas culturales y religiosos, se va desapuntando de sus filas y busca sus propios caminos para encontrar el sentido y la orientación de sus vidas.

El segundo elemento es la proclamación de la condición de sujeto del ser humano interesado seriamente en la espiritualidad. Los nuevos sujetos religiosos son conscientes de que estamos en una época en que las personas quieren ser tratadas como adultas, es decir, como seres humanos capaces de tomar la vida en sus manos y de ejercer el derecho a decidir por sí mismas.

\section{Espiritualidad, sí; religión, no, gracias!}

El año pasado estuve dando un curso con otra hermana de mi Congregación a un grupo de religiosas y religiosas encargados de la animación vocacional en sus instituciones. Una de las preguntas que les planteaba era que revisaran cuáles cosas de sus congregaciones podrían tener un "efecto imán" (tener una fuerza de atracción para otras personas) y cuáles podrían tener el "efecto repelente" (que aleja o produce repulsión). No hay que tener mucha imaginación para concluir que lo que gozaba de mayor magnetismo eran aquellos elementos que tenían que ver con la vivencia de una espiritualidad profunda y descomplicada y con el compromiso por la transformación del mundo (lucha por la justicia, opción por los pobres, defensa del medio ambiente, etc.) y los que causaban mayor repulsa eran aquellos ligados al control institucional, a los formalismos y dogmatismos y a la infantilización de las personas. 
Esta pregunta, planteada a unos pocos delegados de congregaciones religiosas, se podría trasladar al ámbito de las religiones. Y creo que las respuestas irían en la misma línea, aunque sin caer en la ingenuidad, pues muchas veces hay cuestiones accesorias que no forman parte de la esencia más profunda de una religión, pero que tienen aún gran poder de atracción, sobre todo para muchas personas que a nivel religioso todavía están en un estadio más bien infantil.

Pero las nuevas generaciones, sobre todo, y las personas que se sitúan como sujetos religiosos adultos no se sienten atraídas por espacios religiosos en los que abundan las normas, los dogmatismos y la burocratización. Hoy día vemos que hay un creciente interés por la espiritualidad, pero no por las religiones en cuanto sistemas institucionalizados de creencias, ritos, normas éticas y sentimientos peculiares por medio del cual el ser humano se comunica con lo divino. Esto se puede apreciar en el declive que se está dando en muchas de las religiones, no sólo fijándonos en el factor numérico como uno de los indicadores, sino también en el de su relevancia en la sociedad.

En estos nuevos tiempos, las instituciones no tienen el peso de antaño, cuando eran consultadas o su palabra era determinante para las personas y los grupos. Hoy la gente busca más bien estar libre de la tutela y del control ejercido por las religiones, sin que ello signifique que la espiritualidad y las intuiciones de las figuras centrales de las religiones pierdan su fuerza de atracción. Por ejemplo, veamos lo que sucede en el cristianismo: muchas personas ya no se identifican con las iglesias, pero sí les atrae la figura de Jesús de Nazaret y su proyecto, y consideran que los evangelios son escritos inspiradores para la humanidad.

Las religiones están en crisis y entrarán en una crisis aún mayor, pero la espiritualidad no. En este sentido, parece que hará realidad la predicción del escritor francés André Malreaux cuando decía que "El siglo XXI será espiritual o no será”, expresión que luego Karl Rahner aplicará al cristianismo en estos términos: “El cristiano del mañana, o será místico o no será”. 
La vuelta a la espiritualidad, aunque como todo puede tener sus peligros, es un buen síntoma de que hay una búsqueda sincera, un anhelo por llegar a lo esencial y trascender el ropaje en el que eso esencial aparece envuelto. El disgusto y la creciente falta de interés por las religiones no tiene que ver tanto con la sabiduría y el camino hacia Dios que ellas nos pueden ofrecer, sino que el problema reside en la envoltura en que eso nos viene presentado.

Estos son tiempos en que la gente busca "menos religión y más espiritualidad"4. Esta búsqueda lo que pretende en el fondo es devolvernos a nuestro origen o a lo más original, a esa especie de paraíso perdido y olvidado por las mismas religiones. En realidad, las religiones surgen para ayudar a cuidar esa experiencia originaria y ofrecer a las personas los medios para cultivarla. Es una cuestión que las religiones no deben olvidar. Como tampoco se puede olvidar que la espiritualidad es anterior a las religiones y que la función de las instituciones religiosas debería consistir en mantener encendida y ayudar a avivar esa llama original, que, de algún modo, está presente en todo ser humano.

La cuestión de la relación entre religión y espiritualidad está dando mucho que pensar y que escribir. Algunas simplifican el asunto, pero considero que es una cuestión compleja y no exenta de riesgos y banalizaciones. Tomada en serio, en la relación adecuada entre religión y espiritualidad está en juego nuestra capacidad de ser seres más interreligiosos y transreligiosos, pues la espiritualidad en cuanto vivir desde la profundidad y, en términos cristianos, vivir según el espíritu, tiene mucho menos miedo a cruzar las fronteras y al encuentro con el otro que habita en territorios religiosos desconocidos por nuestra propia tradición.

De todos modos, vivir desde la espiritualidad más que desde la religión supone audacia y lucidez. Para encontrarnos con lo Sagrado, con el Misterio, muchas veces hay que plantearse dar el paso de la religión a la espiritualidad, que

\footnotetext{
${ }^{4}$ En octubre de 2008 la Escuela Feminista de Teología Andalucía (EFETA) realizó el III Seminario Presencial anual y tomamos esta cuestión de la relación entre religión y espiritualidad como nuestro tema de debate y reflexión. Lo hicimos desde una perspectiva feminista planteando como lema "Mujeres: ¿menos religión y más espiritualidad? Para más información véase la website de EFETA.
} 
como nos dice Joan Chittister, es un paso peligroso. Ella cuenta cómo la decisión de vivir más desde la espiritualidad que desde la religión la situó en otra coordenada y la llevó a levantar preguntas inéditas:

Aquel día empecé mi propio combate a brazo partido con Dios que ningún catecismo ni credo podía mediar. Y comprendí que, de entonces en adelante, tendría que atreverme a hacer las preguntas que nadie había querido nunca que hiciera (CHITTISTER, 2006, p. 15).

Para terminar este breve apartado quiero tomar prestadas de Martínez Lozano dos imágenes que suelen usarse para ilustrar la relación entre religión y espiritualidad: la copa y el vino; y el mapa y el territorio (FRANCO, 2014, p. 4-5). La espiritualidad es el vino que andan buscando los sedientos y la religión tendría que ser la copa en la que se ofrece el vino. La espiritualidad es el territorio a donde queremos llegar; la religión tendría que ser el mapa que nos sirve de guía y de orientación para no extraviarnos en nuestro camino hacia ese lugar. De aquí que, las instituciones no tendrían otro papel que el de ser buenas mediadoras o parteras de procesos espirituales, tomándose más en serio su papel de facilitar que las personas accedan al vino y lleguen al territorio. Pero la realidad es que muchas veces las instituciones religiosas impiden ese acceso y se convierten en controladoras o neutralizadoras de la capacidad transformadora de la experiencia espiritual. Por eso hay tantas personas que prefiere vivir su espiritualidad al margen de las estructuras religiosas, por temor a que el fuego que llevan dentro sea apagado por la institución religiosa.

\section{La interespiritualidad: el surgimiento de una nueva conciencia religiosa}

El paradigma posreligional nos podría situar en los márgenes de las instituciones religiosas, haciendo búsqueda común con otros buscadores y buscadoras. En el futuro habrá muchas más personas provenientes de distintos trasfondos religiosos que se sentirán más cercanas e interconectadas compartiendo una misma espiritualidad. De hecho esta es una experiencia que ya estamos haciendo, pues muchas veces constatamos que dos personas de distintas religiones 
pueden tener mayor sintonía en su experiencia espiritual y su praxis que con personas de la misma religión.

Dado que a lo largo de la historia ha habido una tendencia a considerar ciertas experiencias y prácticas como propiedad privada de una determinada religión, confesión o congregación religiosa, hoy tenemos el desafío de desprivatizar la riqueza espiritual de cada tradición y declarar como patrimonio de la humanidad aquello que hemos considerado propiedad particular. Todas las instituciones religiosas tenemos que aprender a democratizar y compartir lo que por mucho tiempo hemos considerado como una pertenencia o una herencia no traspasable.

Cuando todo es puesto al alcance de todos y todas y cuando también perdemos el miedo a beber de distintas fuentes, el enriquecimiento es mayor. Cuando una religión se absolutiza tiene dificultades para poner sobre la mesa su sabiduría para que otros también se nutran de ella. Se sitúa en una actitud celosa frente a quienes toman de su mesa algo que es considerado como "propio", como algo de lo que tenemos la "exclusiva" y por tanto es propiedad privada. Es algo que aparece entre los mismos discípulos de Jesús: "Maestro, hemos visto a uno que hacía uso de tu nombre para echar fuera demonios, y hemos tratado de impedírselo porque no es de los nuestros” (Mc 9, 38).

El modelo con el que tradicionalmente han funcionado las instituciones religiosas han sido por lo general el modelo de la casa cerrada en la que quien está fuera no entra y quien está dentro no sale. Más que casa es una especie de prisión. ¿No deberíamos plantearnos la cuestión de la pertenencia a una institución religiosa como una casa abierta donde todos y todas caben y pueden transitar con libertad? ¿No deberíamos poner sobre la mesa la riqueza y la sabiduría de cada cual y nutrirnos de ello más allá de las pertenencias? Quizá ahí descubramos que si muchas veces a lo largo de la historia las pertenencias religiosas nos separan y nos dividen, quizá la vivencia de una espiritualidad interreligiosa y transreligiosa nos 
une y nos reconcilia. Sin duda, mucha gente se encamina a una creencia sin pertenencia y a una práctica religiosa desregularizada. Este va siendo un rasgo distinto del fenómeno religioso en los nuevos tiempos, en los que, como afirmaba hace unos años M.E. Talavera, "lo sagrado moderno estalla de mil maneras; sus migajas se recogen fuera de las instituciones religiosas" (TALAVERA, 2008, p. 62).

La gente tiene una mayor conciencia de ser sujetos capaces de organizarse su mundo religioso y de recrear significados y símbolos religiosos sin enredarse en las cuestiones de la adscripción a una religión. Ciertamente tras esta autonomía y autogestión religiosa también se esconden peligros, como el diseñar una espiritualidad propia light, el habitar en el reino de la religiosidad difusa o construir una religiosidad que recicla retazos de una y otra tradición religiosa.

En un mundo en el cual las fronteras se diluyen y las distancias se acortan, tenemos que ser capaces de vivir una espiritualidad de frontera, encontrándonos con el Misterio más allá de las fronteras y los límites establecidos por las estructuras religiosas. Son muchas las personas que están viviendo su dimensión espiritual más allá de los confines denominacionales. Este situarse en "tierra de nadie" es una especie de rebeldía y de protesta ante estilos religiosos que se mueven en marcos estrechos. Las personas de visión amplia y que anhelan una espiritualidad que les permita moverse con libertad, sienten que se asfixian en los espacios cerrados y controlados. Todo esto representa un serio desafío para cualquier institución religiosa. La espiritualidad nos puede lanzar a terrenos desconocidos, nos saca de lo que consideramos nuestro territorio y nos lleva a ser personas liminales, que vivimos en la frontera de nuestra propia religión y nuestras iglesias.

Nos estamos moviendo hoy día en un nuevo paradigma en el que pasamos del miedo a la espiritualidad que no está vinculada a nuestra religión, a un reconocimiento y acogida a la riqueza espiritual de otras tradiciones, sin caer en una religiosidad difusa o una espiritualidad de retazos. Quizá como fruto de la 
globalización de las religiones y de una mayor oferta de bienes simbólicos y de posibilidades de vivir la religación con lo sagrado, nos estamos atreviendo a beber de otras fuentes.

\section{7 ¿Acta de defunción para las religiones?}

Al hablar del paradigma posreligional no podemos pensar que consiste en una disolución de las religiones y que mejor si vamos preparando el funeral de las mismas. Las cosas son mucho más complejas y quizá más que de desaparición o disolución de las religiones tengamos que hablar de una transformación de las mismas, de una reconversión de sus energías espirituales y su poder de incidencia en la sociedad. Quizá se dé o ya se esté dando una "metamorfosis de lo sagrado", pero no una desaparición del fenómeno religioso.

Aunque estamos en una época de crisis de las religiones, ellas seguirán existiendo (aunque M. Corbí no habla tanto de situación de crisis profunda de las religiones, sino del colapso mismo de las religiones, CORBÍ, 2007, p. 17), pero sólo tenderán una fuerza significativa y aportarán algo al mundo aquellas que tengan el coraje de replantearse su razón de ser y sepan ubicarse de otra manera en el nuevo universo cultural.

No considero que haya que plantear la desaparición de las religiones en esta sociedad de grandes y aceleradas transformaciones, sino que lo que debe morir en las religiones será lo que en ellas no encaja dentro de los nuevos moldes culturales. Por eso, aunque Corbí sostiene que la religión está abocada a la desaparición (CORBÍ, 2007, p. 207), hay que considerar que hay algo que no desaparecerá en las religiones y que para nuestro mundo y nuestra sociedad cambiante es bueno y saludable que no cambie.

Lo primero es la dimensión de hondura, los elementos místicos, que en realidad son transreligiosos y de libre circulación. Lo mismo las personas místicas, 
por los cuales suele haber una fascinación que trasciende el ámbito de la pertenencia religiosa y una percepción de que sin ellos y ellas la religión sería, en palabras de Fraijoó, "un museo al que le han robado sus mejores cuadros" (FRAIJÓ, 1998, p. 389). Los elementos místicos y los grandes místicos y místicas, aunque no son propiedad privada de la religión, sí son una levadura aportada por las religiones para fermentar nuestro mundo. Una religión que aporta su levadura (su mística, su espiritualidad) para ayudar a crecer y a transformar a las personas y los grupos, puede sentirse satisfecha de haber cumplido con uno de sus cometidos. Esa es una misión importante. Si con seriedad hace esto, no importa si en un futuro desaparece o disminuyen sus miembros o caen sus estructuras, lo importante es que ha dejado sembrada una buena semilla que será fructificando en diferentes surcos.

En segundo lugar, es saludable que aunque las religiones se actualicen y se pongan en sintonía con los cambios de paradigmas, ellas sigan aportando al mundo lo que en ellas hay de contracultural. Toda religión alberga dentro de sí algunos elementos y prácticas contraculturales, que podríamos denominar como su carácter profético porque son elementos de denuncia que hacen que la religión pueda funcionar como una instancia crítica del orden establecido. Esta función de las religiones es importante, dado que no todo lo que nos viene con el cambio de paradigmas es bueno y constructivo. Cada tradición religiosa debería esforzarse en buscar y potenciar lo que en ella hay de contracultural y aportarlo al mundo y también a otras religiones con las que intercambiar sus elementos místicos y proféticos.

Además de aportar lo contracultural, las religiones deberían preguntarse si en medio de los distintos cambios de paradigmas que se van sucediendo a lo largo de la historia, ellas albergan en su seno algo que pudiera ser considerado metaparadigmático, o sea, que vaya más allá de todo paradigma y que pueda ser válido para iluminar a los seres humanos de todos los tiempos y para conducirlos a un buen vivir y a un buen convivir con las personas y con toda la creación. 
Las religiones tienen que redefinir su papel, su misión y su función en estos tiempos en que las personas están buscando sentido y orientación desde una postura de adultez y libertad. La gente no quiere una religiosidad cargada de normas, doctrinas y prohibiciones, una religión controladora de la vida de la gente. Más bien lo que tendrá aceptación será un tipo de religión o aquellas instituciones religiosas que no apaguen el espíritu, sino que aviven el fuego. Las religiones entonces tendrán que ser servidoras humildes en la tarea de ayudar a canalizar y a transportar a otros y otras las “energías renovables del espíritu”. De otro modo ellas no tendrán sentido ni serán atrayentes, al menos para quien busca seriamente cultivar su dimensión espiritual y dejar que fluyan sus energías espirituales.

El futuro de las religiones tiene también que ver con la actitud con la que ellas se sitúen ante los grandes clamores de nuestro mundo. Es decir, cómo asumen su parte de responsabilidad ante las magnas cuestiones de nuestro mundo, cómo ejercitan su compasión ante el sufrimiento y su opción por las víctimas, por los empobrecidos. Desde este punto de vista, las religiones tienen que cuestionarse sobre a qué causa sirve lo que ellas predican y proponen, a quién sirve y qué están ofreciendo para la construcción de otro mundo posible. Tienen que interrogarse respecto a su papel como instancias llamadas a levantar una crítica y ofrecer una alternativa a la construcción de un mundo distinto.

Esto supone que ellas deben estar constantemente revisando y redefiniendo lo que es central e innegociable como parte de su esencia y su identidad más profunda, lo cual no está en las normas ni en su ortodoxia, sino en el rol que pueden jugar en la tarea de iluminar el camino de la humanidad ofreciendo sentido y orientación, buscando la justicia y la paz.

Aun en el caso de que las religiones lleguen a ser en un futuro fenómenos marginales, ellas tendrán un aporte que hacer a la humanidad, sobre todo si se saben ubicar y cultivar actitudes nuevas. Así, por ejemplo, ellas deben ubicarse de una forma más humilde, abandonando el lenguaje abstracto y grandilocuente y las 
afirmaciones absolutas. Tendrán que dialogar y abrirse a otras formas de interpretar el mundo que nos vienen de otras cosmovisiones y de las nuevas ciencias.

Uno de los ámbitos desafiantes para las religiones es la cuestión de la moral, pues es uno de los aspectos en los que se resiente el cuestionamiento a las religiones. Hoy día, hay en el creyente adulto un cierto malestar, un descontento por la forma en que las religiones tratan ciertos temas de ética, sobre todo aquellos que incumben a la moral sexual que son en los que las religiones suelen estar más vigilantes. No sucede así con los temas de ética social o ética global.

En un futuro las religiones podrían recrearse y redefinir su misión desde una actitud más humilde y dinámica. Por ejemplo, cumpliendo una misión de servicio a la espiritualidad, favoreciendo que las personas hagan experiencias fundantes profundas y no se limiten a cumplir ritos y normas. Las religiones podrían tomarse más en serio su papel de ser iniciadoras para las personas que necesitan hacer una iniciación para la experiencia espiritual. También tendrían que ser acompañantes y cuidadoras de esa experiencia espiritual.

Las distintas tradiciones religiosas de la humanidad tienen aún una reserva espiritual y unos recursos impresionantes que podrían ayudar a la humanización de nuestro mundo y que servirían de orientación para que el ser humano pueda encontrar y expresar el sentido trascendente de su vida. El problema es el recipiente o el molde cultural en el cual se guardan esos recursos. Las religiones se bloquean a sí mismas y se van auto-aniquilando cuando no son capaces de colocar su riqueza en las vasijas nuevas de la cultura de hoy que ya no es la cultura en las cuales ellas surgieron y se desarrollaron. Ciertamente esta tarea no es fácil y a mi juicio constituye el magno desafío que tienen las religiones que quieren seguir aportando lo más más preciado de sus energías y su fuerza transformadora para rehacer nuestro mundo. 


\section{Entrar en la danza: el futuro de las religiones}

Si nos preguntamos por dónde va el problema de fondo de la crisis de las religiones tenemos que ubicarlo en su resistencia al cambio, en su no encarnación en el tiempo de hoy. Al no saber ubicarse en una historia cambiante y en estos modernos tiempos de cambios acelerados, las religiones van perdiendo actualidad y relevancia, van dejando de ser significativas y pasan a ser más bien sistemas caducos, reliquias del pasado. Como dice Corbí, al dirigirse a sociedades estáticas y pre-industriales que ya no existen, las religiones hoy nos han dejado huérfanos y hemos perdido para siempre la guía de los dioses (CORBÍ, 2007, p. 198).

Las religiones nacieron y se desarrollaron en un mundo agrario y en sociedades estáticas, de poca movilidad de las personas y de escasos cambios. ¿Cómo podrían sobrevivir las religiones hoy en una sociedad dinámica, de cambios acelerados y de gran movilidad? ¿Están las religiones dispuestas a adaptarse a la sociedad el conocimiento y al fenómeno de lo urbano, hoy que, como dice Galli, "Dios vive en la ciudad"? (GALLI, 2014).

Es un hecho que la mayoría de las instituciones religiosas no están a la altura de las circunstancias culturales y de los cambios más sobresalientes de nuestro tiempo. Ellas tienen que ponerse en camino para ajustarse a las nuevas tendencias y los nuevos signos de los tiempos. Las religiones siguen ubicadas en el paradigma pre-industrial; muchas de sus prácticas y sus discursos no corresponden a una sociedad evolucionada que ya no se rige por los parámetros correspondientes al mundo agrario y a todo un sistema de cuño autoritario y patriarcal. A las religiones les falta un gran camino que recorrer para responder a las exigencias de la sociedad del conocimiento, de las sociedades dinámicas y de la innovación. Las religiones mantienen unas prácticas y un lenguaje que choca para la sensibilidad actual. Ellas tienden a ser muy repetitivas y poco innovadoras. Por eso no interesan a gente inquieta y, principalmente las generaciones jóvenes. 
El modelo religioso agrario, autoritario y patriarcal, resulta poco atrayente en un mundo en el que, aún viviendo en zonas rurales, ya las personas participan de la modernidad y están conectados a un mundo globalizado, a nuevas ideas y nuevas formas de sentir y de pensar a través de las modernas Tecnologías de la Información y la Comunicación (TICs). Las formas autoritarias, la imposición sobre qué debo hacer, cómo debo practicarlo causa cierto rechazo en un mundo en el que las personas queremos ser sujetos adultos y cada vez más reclamamos el derecho a decidir y a disentir.

Por otro lado, las religiones que han hecho de la ideología patriarcal un principio importante e inamovible dejan de ser atractivas para las mujeres y los hombres que están en búsqueda de un nuevo paradigma en el que las mujeres no sean seres de segunda categoría, ciudadanas de segunda clase. En estos momentos estamos asistiendo a una crítica creciente y generalizada a todas las religiones en lo que respecta a su carácter androcéntrico-patriarcal. Esta no es una cuestión sólo de un conflicto entre las mujeres que van despertando y tomando conciencia de que no quieren una religión o unas prácticas religiosas de las que ellas son simples consumidoras o son objetos, sino que es cuestión de quienes perciben desde hace rato la obsolescencia de un sistema religioso que realiza algunas prácticas que en el mundo de hoy no sólo no tienen sentido, sino que resultan chocantes y en ocasiones insultantes. Tal es el caso de una organización de rituales y del ejercicio del poder de la palabra ejercido sólo o mayoritariamente por varones. Es curioso que en un mundo que ha evolucionado tanto y en el que a nivel civil las mujeres han conquistado mayores espacios y mayor protagonismo en la toma de decisiones y reclamen su mayoría de edad, las personas que normalmente ejercen la mediación con lo sagrado sean sólo los varones. Esta es una situación que se da no sólo en la religión cristiana, sino también en muchas otras tradiciones religiosas.

El desfase que se da entre las prácticas religiosas instituidas por las religiones y los cambios en las sociedades modernas, muchas veces es abismal. Muchas prácticas, hábitos y discursos que las religiones consideran normales y hasta queridos por Dios, realmente son anormales en este cambio de época. Si las 
religiones son fenómenos culturales y las culturas están cambiando drásticamente, tenemos que preguntarnos en qué pie se sostendrán las religiones en el futuro. Es esta situación la que lleva a Corbí a hacer afirmaciones radicales como ésta: " $L a$ estructura cultural en la que se sustentaban las religiones está agotada, muerta, y debe, por tanto, ser abandonada, porque es un perjuicio para las condiciones culturales de las nuevas sociedades industriales”(CORBÍ, 2007, p. 204).

El cambio de época al que estamos asistiendo es un tiempo de movimiento. Todo está en un dinamismo y en un fluir constante que exige flexibilidad y agilidad. Es tiempo de danza (danza proviene del sánscrito y significa "anhelo de vivir"), de aprender a llevar el ritmo de la historia, el ritmo de los grandes cambios. Es tiempo de facilitar experiencias gozosas, de buena convivencia, de armonía e interconexión, tras una larga historia en que las religiones, en general, han destacado más bien por su rigidez, su seriedad y sentido del sacrificio; han destacado más por enfatizar el "valle de lágrimas" y por ser "aguafiestas" de la felicidad humana; han sido más propensas al dogmatismo y a las posturas inflexibles; han sido creadoras o cómplices de situaciones de conflicto, guerra y confrontación; y han estado aisladas unas de otras, con actitudes de autosuficiencia y de rivalidad que las han incapacitado para dialogar y para unir fuerzas, aportando lo mejor de sí para transformar la realidad de injusticia de nuestro mundo.

Si las religiones no quieren quedarse fuera de la danza de la vida, tienen que desaprender ciertos hábitos ya caducos, aprender nuevos pasos y sobre todo saber llevar el ritmo de la historia. Es decir, incorporarse a la danza que ya hace mucho viene bailando nuestra historia. 


\section{Conclusión}

Las religiones, aunque están en crisis y en estado de cuestionamiento, todavía pueden tener futuro si son capaces de entrar en la danza y seguir el ritmo de la corriente de vida y de energía creadora y transformadora que está fluyendo en nuestro mundo. El futuro de las religiones guarda relación con su capacidad para regenerarse y retomar sus intuiciones más profundas y originales y llevarlas al círculo de la danza como su aporte propio a esa corriente de la vida. Para entrar en una danza hay que eliminar los bloqueos y hacerse flexible. Para danzar hay que ser libre, pues es un ejercicio de libertad y de dinamismo para hacer que fluya lo mejor que tenemos. Estos son los ingredientes que necesitan cultivar las religiones para poder entrar en la danza. De lo contrario se quedarán fuera de la danza, acaso como simples espectadoras (y ojalá no como controladoras o censuradoras) de los grandes cambios que está ocurriendo en nuestro mundo. Es más interesante y más gozoso entrar en la danza!

\section{REFERENCIAS}

ARMENDÁRIZ, L. et al. La religión en los albores del siglo XXI. Forum de Deusto, Bilbao: Ed. UD, 1994.

BERGER, P. El dosel sagrado: elementos para una sociología de la religión. Buenos Aires: Amorrortu, 1971.

BERGER, P. Religion in a Globalizing World. December 4, 2006. Disponible en: <http://www.pewforum.org/2006/12/o4/religion-in-a-globalizing-world2/>. Acceso el 12 oct. 2014 .

BERGER, P. Rumor de ángeles: la sociedad moderna y el descubrimiento de lo sobrenatural. Barcelona: Herder, 1975.

CAROZZI, M. J.; FRIGERIO, A. Los estudios de la conversión a nuevos movimientos religiosos: perspectivas, métodos y hallazgos. In: CAROZZI, M. J.; FRIGERIO, A. (Ed.). El estudio científico de la religión a fines del siglo XX. Buenos Aires: CEAL, 1994. p. 17-53.

CHITTISTER, J. Ser mujer en la Iglesia. Memorias espirituales. Santander: Sal Terrae, 2006. 
CORBÍ, M. Religión sin religión. Madrid: PPC, 2005.

CORBÍ, M. Hacia una espiritualidad laica: sin creencias, sin religiones, sin Dios. Barcelona: Herder, 2007.

CASALDÁliGA, Pedro. Que Deus? Que religião? Agenda Latinoamericana, 2011. Disponible en:

<http://www.servicioskoinonia.org/agenda/archivo/portugues/obra.php?ncodigo=331 $>$. Acceso el 15 enero 2013.

COX, H. La ciudad secular: hacia una teología postmoderna. Santander: Sal Terrae, 1985 .

EFETA - Escuela Feminista de Teología Andalucía. Mujeres: ¿̇menos religión y más espiritualidad? Disponible em: <www.efeta.org>. Acceso el o9 setp. 2014.

FRAIJÓ, M. A vueltas con la religión. Estella: Verbo Divino, 1998.

FRANCO, LAILA. "El camino espiritual es reconocer quiénes somos y conectarnos a ello". Entrevista a Enrique Martínez Lozano, psicoterapeuta y teólogo. Alandar, Madrid, v. 31, n. 304, p. 4-5, 2014. Disponible en: <http://www.alandar.org/spipalandar/IMG/pdf/pdfalandar304.pdf>. Acceso el 12 feb. 2014.

FRIGERIO, A. Desregulación del mercado religioso y expansión de nuevas religiones: Una interpretación desde la oferta. 2000. Disponible en: <http://www.alejandrofrigerio.com.ar/publicaciones/religion/Frigerio\%20_Paradigma_ Mercado_BIB_200o.pdf>.Acceso el 10 sept. 2014.

GALLI, Carlos M. Dios vive en la ciudad. Hacia una nueva pastoral urbana a la luz de Aparecida y del proyecto misionero de Francisco. Barcelona: Herder, 2014.

JOHNSON, E. La Que Es: El misterio de Dios en el discurso teológico feminista, Barcelona, Herder, 2002.

MARDONES, J.M. Matar a nuestros dioses: un Dios para un creyente adulto. Madrid: PPC, 2006.

MARDONES, J.M. Para comprender las nuevas formas de religión. Estella: Verbo Divino, 1994.

MARTINI, Cardenal. iViva el Cardenal Martini! Texto auténtico de su 'Testamento espiritual' .8 de Agosto de 2012. Disponible en:

<http://www.religionenlibertad.com/articulo.asp?idarticulo=24633>. Acceso el 12 oct. 2014.

PANIKKAR, R. Pensamiento científico y pensamiento cristiano. Santander: Sal Terrae, 1994. 
SEQUEIROS, L. et al. Tendencias 21 de las religiones. Córdoba: Bubok, 2014.

TALAVERA, M. E. La escena religiosa en mutación. Transformaciones del simbolismo religioso en la historia contemporánea venezolana. Revista Tierra Firme, Caracas, v. 26, n. 101, p. 61-78, Marzo 2008.

TAMAYO ACOSTA, J.J. Otra teología es posible: pluralismo religioso, interculturalidad y feminismo. Barcelona: Herder, 2011.

VATTIMO, G. Después de la cristiandad: por un cristianismo no religioso. Barcelona: Paidós, 2004. 